\title{
$\mathrm{EA}$ 거버넌스와 EA 역량에 관한 실증적 연구 : 공공기관을 중심으로
}

\author{
김 기 백*, 이 철 규**, 유 왕 진***, 문 종 범****
}

\section{An Empirical Study on EA Governance and EA Competency of Public Agencies}

\author{
Gi-Baek Kim* , Cheol-Gyu Lee** , Wang-Jin Yoo***, Jong-Beom Moon****
}

\section{요 약}

최근 정보시스템의 중복투자 방지와 상호운영성 증대를 위해서 효율적이고 체계적으로 정보자원관리(IRM)를 위해 $\mathrm{EA}$ (Enterprise Architecture)를 도입 활용하고 있으며, 이러한 $\mathrm{EA}$ 를 더욱 성과지향적으로 통제관리하기 위해 $\mathrm{EA}$ 거버넌스를 도입하고 있는 가운데 본 연구에서는 국내 공공기관의 $\mathrm{EA}$ 거버넌스 수준과 $\mathrm{EA}$ 역량에 대한 관련성을 실증적으로 수행하였다. $\mathrm{EA}$ 를 도입 활용하는 정보화 부서에 종사하는 총190명을 대상으로 관련 가설을 수립하여 구조방정식을 이용하여 통계적으로 검증하였다. 그 결과, $\mathrm{EA}$ 거버넌스의 $\mathrm{EA}$ 기능·프로세스, $\mathrm{EA}$ 조직과 인력 수준 모두 도입 후 $\mathrm{EA}$ 관리와 활용 역량에는 영향을 미치지만 $\mathrm{EA}$ 조직과 인력 수준이 $\mathrm{EA}$ 수립에는 그 다지 영향을 미치지 못하는 것은 대부분의 공공기관들이 처음 $\mathrm{EA}$ 도입구축 시 관련 예산 부족 등으로 전문 인력 미확보 와 전담 조직을 미처 갖추지 못하고 외부 전문가에 의존한 결과라고 볼 수 있다. 특히 $\mathrm{EA}$ 거버넌스가 단계적으로 $\mathrm{EA}$ 수립 역량의 수준에 따라 두 번째 단계인 $\mathrm{EA}$ 관리 역량에 영향을 미치고, 또한 $\mathrm{EA}$ 관리 역량의 수준이 세 번째 $\mathrm{EA}$ 활용 역량에 충분히 영향을 주는 것으로 검증결과가 규명되었다.

- Keyword : ITA, EA, EA 거버넌스, EA 역량

\section{Abstract}

EA, efficient and hierarchical Information Resource Management(IRM) tool of Korean public agencie is one of the core of carrying forward the $\mathrm{e}$-Government initiative. The objective of the paper is to study empirically whether using EA Governance for Controlling EA is related with their

• 제1저자 : 김기백 • 교신저자 : 이철규

- 투고일 : 2012. 02. 02, 심사일 : 2012. 02. 22, 게재확정일 : 2012. 03. 25.

* 건국대학교 대학원 벤처전문기술학과 (Dept. of Venture Tech. \& Mgt, KonKuk University)박사수료

** 건국대학교 기술경영학과 (Dept. of Tech. Mmanagement, KonKuk University)교수

*** 건국대학교 산업공학과(Dept. of Industrial Engineering, KonKuk University)교수

**** 건국대학교 벤처전문기술학과(Dept. of Venture Tech. \& Mgt, KonKuk University)교수 
EA competency or not. the 190 person in charge of Information System service division are included for analysis. The various hypotheses established are validated by structural equation in SPSS and AMOS 18.0. The results shows that EA management and EA utilization of EA competency level was affected by EA Function, EA Organization and EA Human Resource of exogenous variable EA Governance but EA implementation level was not affected by EA Organization and EA Human Resource. also we investigated that the EA management level of endogenous variable EA competency was affected positively by EA implementation level and the EA utilization level of was affected positively by EA management level by stages.

- Keyword : ITA(Information Technology Architecture), EA(Enterprise Architecture), EA Governance, EA competency

\section{I. 서 론}

오늘날 정보시스템은 조직의 경영 및 업무를 단순히 지원 하는 수단에서부터 전략적 도구에 이르기까지 없어서는 안 되 는 존재가 되고 있다.

이러한 경쟁력 수단으로 조직은 다양한 온라인 및 오프라 인의 형태의 정보시스템을 도입 및 활용에 지속적으로 정보화 예산을 확대 투자하고 있으며 이로 인하여 날로 확대되어 가 는 정보시스템 복잡성과 중복 투자가 늘어가고 각종 시스템 간 연계가 원활하지 않아 조직 차원에서 정보시스템으로 인한 정보자원을 통합적이고 효율적으로 운영관리 및 통제하는 수 단이 필요하게 되었다[1][2].

이렇게 복잡 다양한 문제에 당면한 미국의 경우 본격적으 로 해결하기 위해 1990년대부터 정보기술아키텍처(ITA, Information Technology Architecture 이하 'ITA'라 함) 개념을 도입하여 2000년 개정된 $\mathrm{OMB}$ ((Office of Management and Budget) A-131040에서 EA(Enterprise Architecture)로 개정되어 현재 연방 및 중앙정부기관에서 정 보자원관리를 위한 기본수단으로 도입하여 활용측면에서 성숙 단계에 이르고 있다.

또한 일본의 경우 $\mathrm{EA}$ (Enterprise Architecture 이하 'EA'라 함)의 목적을 중복시스템의 배제로 정의하고, 경제산 업성의 주도하에 각 관청의 정보시스템을 공통화 해 간다는 계획과 유사한 기능을 갖춘 정보시스템을 통합한다는 가이드 라인을 2003년에 작성하고 업무 - 정보시스템 최적화 계획수 립 및 지침 제2판을 2004년 2월에 발표하는 등 본격적인 $\mathrm{EA}$ 활동을 하고 있다[3]. 우리나라에서도 2000년 초부터 몇몇 대기업 및 금융기관에서 $\mathrm{EA}$ 도입 및 활용을 시작하여 2003
년 전자정부 31 대 중점추진과제로 '범정부 ITA 적용'이 채택 된 이후 2005년 12 월 '정보시스템의 효율적 도입 및 운영 등 에 관한 법률'이 제정되었고 그 후 2008년 ' $\mathrm{EA}^{\prime}$ '법률이 일부 개정되어 2010 전자정부법 개정으로 정보기술아키텍처(정보 화설계도)의 도입·운영 및 정보시스템에 대한 감리제도 운영 등의 주요내용을 통합적으로 규정하여 $\mathrm{EA}$ 의 도입 및 적용을 의무화 하는 등 공공부분의 $\mathrm{EA}$ 도입, 활용은 더욱 활발하게 진행되고 있는 추세이다.

국내에서 이렇게 활발하게 $\mathrm{EA}$ 도입 및 활용이 이루어지고 있고, 지속적인 $\mathrm{EA}$ 의 진화관리 활동을 통한 최적화 측면에서 $\mathrm{EA}$ 를 통제하고 체계적이고 효율적으로 관리하기 위해 조직, 인력과 기능 - 프로세스 체계 등 구성요소를 포함하는 전사적 IT거버넌스를 통해 $\mathrm{EA}$ 를 함께 도입하거나 $\mathrm{EA}$ 와 같이 $\mathrm{EA}$ 거버넌스를 도입 운영하는 사례가 점차적으로 늘어가고 있다.

이에 국내외적으로 $\mathrm{EA}$ 와 관련하여 전사측면에서 IT거버 넌스와 IT역량에 관한 연구와 문헌은 다수 볼 수 있지만 최근 에 $\mathrm{EA}$ 의 기능과 역할이 확대되고 있는 추세에 따라 학문적 실무적으로 관심을 보이고 있는 실정임에도 $\mathrm{EA}$ 거버넌스와 $\mathrm{EA}$ 역량의 관계에 관한 연구는 거의 이루어지지 않고 있다.

따라서 국내외적으로 $\mathrm{EA}$ 거버넌스에 대한 많은 관련 논문 및 문헌자료를 찾아보기에는 아직 이르지만 미국, 일본, 유럽 에서는 국가 공공부문에서 활발하게 도입 활용하고 있으며, 국내에서도 민간기업보다 활발하게 도입 운영하고 있는 공공 부문에서 더욱 $\mathrm{EA}$ 활용 및 역량을 향상시키기 위해 $\mathrm{EA}$ 거버 넌스 필요성을 인지하고 있는 상황에서 실제 도입 수립한 $\mathrm{EA}$ 거버넌스와 조직 $\mathrm{EA}$ 역량의 상호관련성 차원에서 검증하기 위해 시도 되었다.

공공기관에서 도입운영하고 있는 $\mathrm{EA}$ 거버넌스와 $\mathrm{EA}$ 역량 의 상호 관련성을 검증하기 위해 $\mathrm{EA}$ 역량 수준이 $\mathrm{EA}$ 거버넌 스 요인에 따라 어느 정도 영향을 받고 있는지를 실증연구를 
통하여 분석하고자 한다.

제2장에서는 선행 연구에 대한 고찰 등을 통해서 연구가설 이 제시되었으며, 제 3 장에서 연구방법의 개요를 설명하고, 실 증 자료에 대한 통계분석과 수립된 가설에 대한 검증 내용을 상세히 기술하였다. 최종적으로 제 4 장에서 주요내용을 결론 으로 요약하고 시사점을 제시하였다.

\section{II. 관련 연구}

\section{EA 거버넌스}

\section{$1.1 \mathrm{EA}$ 개념}

아키텍처의 개념은 고대 건축에서 인용된 것으로 IT분야 의 '아키텍처'란 시스템의 구성요소, 요소 및 환경간의 상호관 계, 이들의 설계와 전개를 관리하는 원칙들이 포함된 기반 조 직체를 말한다.

이처럼 아키텍처란 용어가 IT분야에서 사용된 것은 1987 년 Zachman이 정보시스템의 복잡성을 해결하기 위해 건축 설계도의 개념을 도입하면서 부터였다[4].

ITA란 용어는 1996년 미국 정보기술관리개혁법(Information Technology Management Reform Act:ITMRA)에서 처음으 로 정의되었고 그 이후 2000 년 미국 예산관리국 $(\mathrm{OMB}) \mathrm{A}-130$ 을 개정하면서 전사적 아키텍처(EA)로 바뀌었대[5].

현재 미국에서는 ITA가 EA란 용어로 사용되고 있으며 국 내에서는 2008년부터 공식적으로 ITA보다는 $\mathrm{EA}$ 를 사용하 고 있다[6].

$\mathrm{EA}$ 에 대한 정의로 ITMRA에서는'행정기관의 전략적인 목 표와 정보자원관리 목표를 달성하기 위해 기존의 정보기술을 발전시키거나 유지보수하고 새로운 정보기술을 조달하기 위 한 통합적인 기반(integrated framework)'이라 했으며 $\mathrm{OMB}$ 에서는 '조직 및 업무활동과 정보기술간의 관계를 현재 의 모습과 향후 추구해 나가야 할 모습을 별도로 정의 해둔 청사진'이라고 정의하고 있다[7].

국내의 경우는 조직의 주요 비즈니스, 정보, 응용시스템, 기술기반구조를 정의하고 이러한 요소가 상호 연계되는 모습 을 총괄적으로 표현한 것으로 정의했고[8], 또한 $\mathrm{EA}$ 를 조직 의 전략적 목표와 연계해 마치 건축을 위한 '도시계획 청사진' 과 같은 역할을 하며, 비즈니스와 IT 양쪽에 프레임워크를 제 공하며, 투자를 안내하고, 비용을 절감하며, 의사결정을 지원 한다[9].

국내 공공부문에서는 법률 제 816 호 8의 일명“ITA법”에 의
해 '일정한 기준과 절차에 따라 업무, 응용, 데이터, 기술보안 등 정보화 구성요소들을 관리하는 것으로 사물/대상을 단순하 게 표현함으로써 의사소통이 확대되어 변화되는 요구를 효과 적으로 수용할 수 있다는 장점 때문에 정보기술에서 매우 중 요한 관리방법이 되고 있다[10].

$\mathrm{EA}$ 효과 측면에서 살펴보면 미국 공공기관 $\mathrm{CIO}$ 의 모임인 $\mathrm{CIO}$ Council의 보고서에 따르면 $\mathrm{EA}$ 를 적용하는 주된 이유 로 정렬(alignment), 통합(integration), 변화(change), 적기출시(time to market), 컨버전스(convergence) 다섯 가지로 언급하면서 $\mathrm{EA}$ 를 통해 조직 미션과 업무기능의 이해, 업무와 IT의 연계, 복잡한 시스템을 관리하기 위한 구조적 (Architecture)관점 제공 등의 효익이 있다고 했다[1]. 미국 의 오하이오주와 미 특허청(United States Patents and Trademark Office)에서는 EA도입을 통해 데이터관리 효율 화 및 유지보수비용을 감소시키고 있으며[11], 국내에서도 국 토해양부, 우정사업본부, 건강보험심사평가원 및 서울시 등 많 은 공기업 및 공공기관에서 정보화 투자예산 절감, 정보시스템 및 데이터의 중복성 제거 등의 효과가 있다고 보고했다[12].

\subsection{EA 역량}

정보기술 역량이란 IT 자원을 취득하여 비즈니스의 전략 도구로 활용하기 위해 IT 자원을 전개하고 IT 전문기술, IT 인적 자원과 같은 IT 자원을 활용하는 역량이다.

정보기술의 하드웨어나 소프트웨어만을 말하는 것이 아니 라 정보기술에 기반을 두는 유무형적 자원을 모두 포함시키는 개념으로서 정보기술 자원들의 적절한 조합이 정보기술 역량 을 창출하고 조직의 이윤을 높이고 비용을 낮춘다는 것을 실 증분석에 의해 주장하였다[13].

정보기술역량을 조직내 정보화를 효과적으로 구현하기 위 한 정보기술조직과 업무조직의 책임을 상호 공유한다는 의미 로 관계역량, $\mathrm{EA}$ 등 정보기술을 통한 업무지원과 조직역량 을 높이는 정보기술 수준인 기술역량 그리고 조직의 업무 및 기회를 정보기술을 통해 해결하는 인력인 인적역량 등 세 가 지 요소로 분류하여 정의하였고[14], 관계역량이 $\mathrm{EA}$ 를 도입 한 조직의 목적인 업무, 데이터, 응용, 기술아키텍처의 상호 연계를 유기적으로 운영하여 정보시스템의 복잡성과 중복성 을 해결할 수 있다고 하였다[6].

또한 IT거버넌스는 기업의 IT역량을 증대시키는 일종의 메커니즘이다[15].

이에 $\mathrm{EA}$ 역량은 조직의 목표 및 전략과 연계하여 전사적 정보화 목표를 달성하기 위한 $\mathrm{EA}$ 체계를 도입 및 관리활용하 기 위한 능력의 정도이며 전사적으로 $\mathrm{EA}$ 를 통한 정보화 성과 를 창출하는 수준을 의미한다. 
이와 같은 IT 역랑을 $\mathrm{EA}$ 관점에서 바라보면 $\mathrm{EA}$ 역량은 $\mathrm{EA}$ 구축지식 및 기술을 통해 수립하는 역량, $\mathrm{EA}$ 업무를 추진 관리하는 역량 그리고 $\mathrm{EA}$ 를 정보화활동에 활용하는 역량인 것이다.

$\mathrm{EA}$ 역량의 구성요소로 $\mathrm{EA}$ 수립역량, $\mathrm{EA}$ 관리역량, $\mathrm{EA}$ 활 용역량으로 정의한다[16][17].

$\mathrm{EA}$ 업무 단계별 역량 차원에서 $\mathrm{EA}$ 구축의 경우에 $\mathrm{EA}$ 수립역 량이 $\mathrm{EA}$ 활용역량에 영향을 미치며, $\mathrm{EA}$ 관리역량이 $\mathrm{EA}$ 역량 과정에서 충분히 조절역할을 한다는 결과를 알 수 있다[18].

따라서 정보화 부문에서 정보기술 역량에 대한 많은 연구 와 문헌의 내용이 $\mathrm{EA}$ 관점에서의 역량으로 내용 전개가 되고 있고, 대부분 $\mathrm{EA}$ 역량의 구성요소가 전사적인 정보기술역량 부문에 공통적으로 포함된다는 것을 알 수 있으며, $\mathrm{EA}$ 수립, 관리 및 활용단계별로 역랑을 나누어져 상호 영향을 줄 수 있 다는 것을 알 수 있다.

\subsection{EA 거버넌스}

$\mathrm{EA}$ 거버넌스란 $\mathrm{EA}$ 관리를 위한 조직과 구성원의 명확한 역할과 책임을 정의하고 $\mathrm{EA}$ 의 활용과 관리를 위한 프로세스 를 수립하며, 구성요소와 모델 관리를 위한 절차와 지침을 의 미한다[19].

$\mathrm{EA}$ 거버넌스는 IT거버넌스의 하위 개념으로 $\mathrm{EA}$ 관리체계 [20][3]로서 조직의 전사적 IT거버넌스의 부분적 역할과 책 임을 명확히 가진다.

특히 조직에서 정보화 업무를 수행하는 데 있어 조직 상호 간에 중복 없이 진행되도록 조정하는 것은 물론, 정보화 기획 에서 정보화 서비스 제공까지의 모든 정보화 활동과정에서 $\mathrm{EA}$ 를 통해서 의사결정의 일관성을 유지하며 수립된 $\mathrm{EA}$ 를 준 수함으로써, 정보화 수행 능력 전체에 대한 선진화를 실현시 키는 것과 동시에 $\mathrm{EA}$ 가 제공할 수 있는 전반적인 가치를 확 보 가능하게 해 주는 정보자원관리의 전체 관점에서 $\mathrm{EA}$ 거버 넌스로 정의된다.

기업거버넌스, IT거버넌스, $\mathrm{EA}$ 거버넌스의 관계를 그림 1 에서 보여주는 처럼 $\mathrm{EA}$ 거버넌스는 기업의 전사적 거버넌스 하에서 IT거버넌스를 전제로 하여 도입 활용되어야 한다[21].

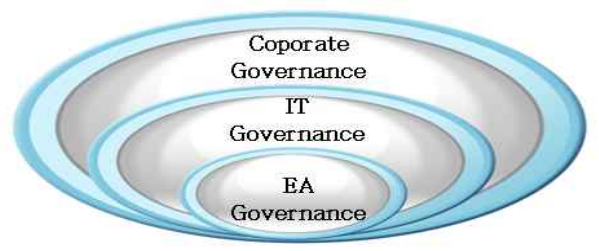

그림 1. 거버넌스 구조 Fig. 1. Govemance Structure
본 연구에서의 $\mathrm{EA}$ 거버넌스 관련 변수는 전자정부에서 법 제도적 기반에서 아키텍처 구축 시 적용되고 있는 거버넌스인 $\mathrm{EA}$ 관리체계 구성요소인 $\mathrm{EA}$ 기능·프로세스체계, $\mathrm{EA}$ 조직체 계, EA인력양성체계를 연구의 실정에 맞게 적용하였다[20].

$\mathrm{EA}$ 기능 - 프로세스체계는 $\mathrm{EA}$ 를 수립하고, 유지 관리하는 등, $\mathrm{EA}$ 의 모든 활동과 관련된 $\mathrm{EA}$ 업무 수행내용 및 절차를 말한다.

$\mathrm{EA}$ 기능 - 프로세스체계를 구축한 결과로는 $\mathrm{EA}$ 관리 및 활 용을 위해 수립해야 할 $\mathrm{EA}$ 업무 수준의 공통기준 및 지침으로 서 $\mathrm{EA}$ 원칙을 수행하기 위해 해야 할 업무요소에 대한 분류 및 내용을 나타내는 EA업무체계 및 수행방법에 대한 문서화 된 정의 및 업무활동을 위해 필요한 기준인 $\mathrm{EA}$ 지침 및 절차 가 필요하며 무엇보다 조직 전체 정보화 업무체계와의 통합성 및 연계성을 확보하여야 한다.

$\mathrm{EA}$ 조직체계는 조직 목표를 달성하기 위해 $\mathrm{EA}$ 수립, 관리 및 활용을 위해 요구되는 관련 업무기능을 수행하는 각 담당 자의 관계, 책임 및 역할을 의미하는 것으로 $\mathrm{EA}$ 관련 제반당 사자, 의사결정에 대한 권한이양 관계, 조직도 및 업무분장관 계 $\mathrm{EA}$ 조직체계 수립 시에는 전체 조직 및 정보화 부분 조직 체계와의 일관성을 확보하는 것이 무엇보다 중요하다. 또한 $\mathrm{EA}$ 조직체계의 최종적으로 구축한 결과로서 전사 정보화 부 분 조직체계로 구성되어야 한다.

$\mathrm{EA}$ 인력체계는 정보화 조직 내에서 $\mathrm{EA}$ 도입계획, 구축, 관리를 담당할 아키텍처 영역별 아키텍트 및 $\mathrm{EA}$ 를 활용하고 준수할 업무조직의 간접적 $\mathrm{EA}$ 관련 당사자들의 $\mathrm{EA}$ 지식과 $\mathrm{EA}$ 역량을 갖춘 조직 내부 구성원을 말하며 $\mathrm{EA}$ 의 수립, 관 리 및 활용을 위해 필요한 $\mathrm{EA}$ 역량과 $\mathrm{EA}$ 기반 정보자원관리 조직 및 업무체계에 일관적인 정보자원관리 직무분류, 각 직 무별 수행 역할, 필요한 $\mathrm{EA}$ 역량 나타내는 아키텍처 직무체 계도 필요한 것이다.

또한 적절한 $\mathrm{EA}$ 인력체계가 확보되기 위해서는 $\mathrm{EA}$ 교육과 정뿐만 아니라 조직에 요구되는 각 아키텍처별 $\mathrm{EA}$ 관련 역량, 이러한 역량에 맞춘 직무별 차별화된 $\mathrm{EA}$ 교육 프로그램 등이 체계적으로 구성되어야 한다.

따라서 $\mathrm{EA}$ 를 통제관리하는 $\mathrm{EA}$ 거버넌스는 정보화 활동의 투명성 및 상호운용성 증대를 위해 필요한 $\mathrm{EA}$ 역량과 관련성 이 있지만 $\mathrm{EA}$ 활동의 각 단계 별로 필요한 역량과 관계에 대 한 구체적인 연구가 부족하며 $\mathrm{EA}$ 의 활용 극대화를 위해서 상 호 관계에 대한 연구가 필요한 실정이다.

\section{III. 본 론}


1. 연구모형 및 가설

\section{1 연구모형}

각종 문헌 및 연구자료를 통하여 알 수 있듯이 IT거버넌스 관리통제 하에서 정보자원관리 도구인 $\mathrm{EA}$ 를 체계적으로 운 영하여 정보시스템의 복잡성과 중복성 배제에 효과가 있다는 것은 $\mathrm{EA}$ 수립, 관리 및 활용단계에 제대로 운영할 수 있는 필 요한 역량에 영향이 미친다고 볼 수 있다.

하지만 협의적인 EA 거버넌스가 가지는 기능의 범위과 역 할을 통해서도 $\mathrm{EA}$ 수립, 관리 및 활용단계에서의 역량에 유사 한 결과를 기존 문헌에서는 나타나지 않는 실정이다.

따라서 본 연구는 $\mathrm{EA}$ 아키텍처를 도입하여 활용하고 있는 국내 공공부문을 대상으로 조직의 $\mathrm{EA}$ 거버넌스가 투명하고, 효율적 측면에서 $\mathrm{EA}$ 역량에 어느 정도 영향을 주고 있는지 알아보기 위해 연구모형을 설정했다.

정보화 업무활동과 정보자원관리를 효율적으로 지원하기 위해 $\mathrm{EA}$ 를 도입 구축하면서 체계적인 통제 관리를 위해 $\mathrm{EA}$ 거버넌스를 보다 계획적으로 도입 적용하지만 $\mathrm{EA}$ 거버넌스 의 핵심 구성요소로서 $\mathrm{EA}$ 기능 - 프로세스, $\mathrm{EA}$ 조직, $\mathrm{EA}$ 인력 등이 표준적으로 선정되어 적용하지 않고서는 적절하게 구조 화 된 $\mathrm{EA}$ 거버넌스를 실현하는 것은 어려울 것이다.

따라서 $\mathrm{EA}$ 거버넌스의 핵심구성요인인 $\mathrm{EA}$ 기능-프로세 스, $\mathrm{EA}$ 조직 그리고 $\mathrm{EA}$ 인력의 상호 체계적인 구성을 통한 활 동이 궁극적으로 $\mathrm{EA}$ 수립, 관리 및 활용 단계별로 업무를 수 행하는데 필요한 역량에 기여할 수 있을 것이다.

결국 전사적인 정보화 활동의 중복성 배제 및 상호운용성 을 증대시켜줄 수 있는 $\mathrm{EA}$ 의 단계별 활동을 지속적이며 투명 하고, 효율적으로 관리 통제하기 위한 목적을 가진 $\mathrm{EA}$ 거버 넌스가 EA의 활동 단계별로 요구되는 역량에 영향을 미치는 지 심도있는 관계분석을 통하여 $\mathrm{EA}$ 거버넌스의 역할과 중요 성을 알아 보고자 한다.

이를 위해 본 연구에서는 연구 목적을 달성하기 위해 구조 방정식 모형을 사용하려고 한다. 이는 여러 개의 다중회귀분 석을 이용한 인과관계 분석을 하나의 구조방정식 모형으로 표 현하기 위한 목적이다.

이러한 실증연구를 통해 분석하고자 하는 주제를 모형화하 면 그림 2와 같다.

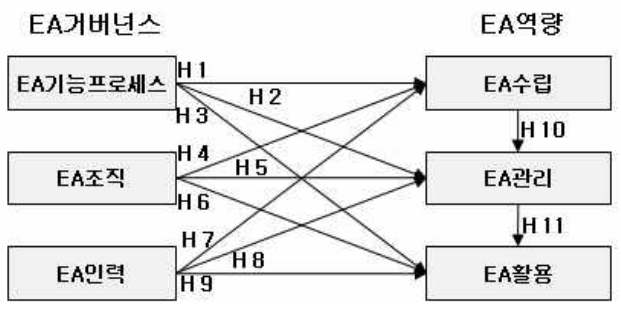

그림 2 연구 모형 Fig. 2 Study Mbdel

1.2 연구가설

기존의 $\mathrm{EA}$ 거버넌스와 $\mathrm{EA}$ 역량에 대한 문헌과 연구를 바 탕으로 $\mathrm{EA}$ 거버넌스에 따라 조직의 $\mathrm{EA}$ 역량이 차이가 있을 것이라고 생각하고 아래와 같은 가설을 설정하였다.

가설 $1: \mathrm{EA}$ 거버넌스의 요인 항목인 $\mathrm{EA}$ 기능 - 프로세스 가 $\mathrm{EA}$ 수립역량에 유의한 영향을 미칠 것이다.

가설 $2: \mathrm{EA}$ 거버넌스의 요인 항목인 $\mathrm{EA}$ 기능 - 프로세스

가 $\mathrm{EA}$ 관리역량에 유의한 영향을 미칠 것이다.

가설 $3: \mathrm{EA}$ 거버넌스의 요인 항목인 $\mathrm{EA}$ 기능 - 프로세스

가 $\mathrm{EA}$ 활용역량에 유의한 영향을 미칠 것이다.

가설 4:EA 거버넌스의 요인 항목인 $\mathrm{EA}$ 조직이 $\mathrm{EA}$ 수립 역량에 유의한 영향을 미칠 것이다.

가설 $5: \mathrm{EA}$ 거버넌스의 요인 항목인 $\mathrm{EA}$ 조직이 $\mathrm{EA}$ 관리 역량에 유의한 영향을 미칠 것이다.

가설 $6: \mathrm{EA}$ 거버넌스의 요인 항목인 $\mathrm{EA}$ 조직이 $\mathrm{EA}$ 활용 역량에 유의한 영향을 미칠 것이다.

가설 $7: \mathrm{EA}$ 거버넌스의 요인 항목인 $\mathrm{EA}$ 인력이 $\mathrm{EA}$ 수립 역량에 유의한 영향을 미칠 것이다.

가설 8: $\mathrm{EA}$ 거버넌스의 요인 항목인 $\mathrm{EA}$ 인력이 $\mathrm{EA}$ 관리 역량에 유의한 영향을 미칠 것이다.

가설 $9: \mathrm{EA}$ 거버넌스의 요인 항목인 $\mathrm{EA}$ 인력이 $\mathrm{EA}$ 활용 역량에 유의한 영향을 미칠 것이다.

또한 $\mathrm{EA}$ 활용기간에 차이가 있겠지만 $\mathrm{EA}$ 거버넌스의 각 외생변수 항목이 내생변수인 $\mathrm{EA}$ 수립, $\mathrm{EA}$ 관리 및 $\mathrm{EA}$ 활용 단계별로 실질적인 영향을 미치는지 검증하기 위해 구성하였 다.

가설 $10: \mathrm{EA}$ 수립역량이 $\mathrm{EA}$ 관리역량에 유의한 영향을 미 칠 것이다.

가설 11 : $\mathrm{EA}$ 관리역량이 $\mathrm{EA}$ 활용역량에 유의한 영향을 미 칠 것이다.

1.3 변수의 조작적 정의

1.3.1 EA 거버넌스 
본 연구에서 $\mathrm{EA}$ 거버넌스의 측정요소는 행정자치부[20] 의 공공부문 $\mathrm{EA}$ 거버넌스 프레임워크를 기본으로 $\mathrm{EA}$ 기능 프로세스, $\mathrm{EA}$ 조직, $\mathrm{EA}$ 인력 세 가지 항목을 수정 보완하여 정의하였고, $\mathrm{EA}$ 기능·프로세스 요소에 $\mathrm{EA}$ 원칙, $\mathrm{EA}$ 관리시 스템, $\mathrm{EA}$ 규정 - 지침 등 구성 요소를 포함시켰다.

관련 항목의 조작적 정의 및 관련 연구는 표 1 과 같다.

\subsubsection{EA 역량}

본 연구에서는 미국 예산관리국 $\mathrm{OMB}$ 의 Enterprise Architecture Assessment Framework : $\mathrm{EAAF}$ )를 근간 으로 만들어진 국내 공공부문에서 매년 측정하는 성숙도 모델 에 기반하여, 본 연구 실정에 초점을 맞추어 일부 수정하여 적용하였으며, $\mathrm{EA}$ 수립역량은 업무아키텍처, 데이터아키텍처, 응용아키텍처, 기술아키텍처, 보안아키텍처, 이행전략계획 등 을 말하며 $\mathrm{EA}$ 관리역량은 $\mathrm{EA}$ 정책, $\mathrm{EA}$ 추진관리체계, $\mathrm{EA}$ 교 육체계, 아키텍처 정보관리 등을 포함하고 있으며 $\mathrm{EA}$ 활용역 량은 전략연계, 기획예산, 사업 관리, 성과관리 등으로 구성 하고 있다[22][23].

각 개별 항목의 조작적 정의 및 관련 연구는 표 2 와 같다.

\section{2. 연구 및 가설검증}

\section{1 설문의 구성}

본 연구를 위해 구성한 설문은 $\mathrm{EA}$ 거버넌스와 $\mathrm{EA}$ 역량의 측정항목을 기반으로 $\mathrm{EA}$ 기능-프로세스 13 개 문항, $\mathrm{EA}$ 역
량 13 개 문항, 그리고 인구통계학적 분석을 위한 7 개 문항 등 총 30 개 문항으로 구성되어 있다.

인구통계학적 분석을 위한 문항을 제외하고 다른 모든 문 항은 리커트식 5점 척도로 응답하도록 하였다.

\section{2 연구 범위 및 수집 분석 방법}

본 연구의 범위는 2010년 5월 '전자정부법'에 따른 $\mathrm{EA}$ 의 도입 및 적용 의무화에 따라 중앙행정기관 40개, 지방자치 단 체 16 개, 기타 공공기관 70 개의 정보화 부서에 종사하는 총 190 명을 대상으로 설문조사를 실시하였다.

분석 자료는 2010년 10월 초순부터 12월 말까지 직접방 문, 이메일, 우편 등을 통해 총 190부 배포하여 이 중에서 약 $83 \%$ 인 158 부를 회수하였다. 이 중 2 부는 불성실성로 제외 하여 본 연구의 분석에는 156 부를 최종 표본으로 선정하였으 며 이를 본 연구의 실증분석을 위해 사용하였다.

참고로 2009년 $\mathrm{EA}$ 역량을 나타내는 $\mathrm{EA}$ 성숙도 측정에서 전체기관의 종합평균 2.60 수준이며 $\mathrm{EA}$ 활용에 있어 $\mathrm{EA}$ 관련 조직과, 프로세스 체계 등을 갖추어 조직 내부적으로 더욱 내 재화 할 필요성을 느끼는 상황을 고려하여 선정하였기에 조사 대상의 대표성은 충분히 확보하였다고 볼 수 있다.

자료의 통계처리는 SPSS 18.0 윈도우용 통계패키지를 이 용하였다. 통계의 처리는 본 연구에 사용된 측정도구의 신뢰 성 분석을 하였으며 측정된 변수의 타당성을 검증하기 위해 요인분석을 하였다. 가설을 검증하기 위해 $\mathrm{EA}$ 도입기관을 대

표 1. $E A$ 거버넌스의 조작적 정의 및 관련 연구

Table 1. EA Govemance operational definition \& reference6

\begin{tabular}{|c|c|c|c|c|}
\hline \multicolumn{2}{|r|}{ 구분 } & 조작적 정의 & 측정 향목 & 관련 연구 \\
\hline \multirow{3}{*}{$\begin{array}{l}\mathrm{E} \\
\mathrm{A} \\
\text { 거버 } \\
\text { 넌스 }\end{array}$} & $\begin{array}{l}\text { EA기능 } \\
\text { 프로세스 }\end{array}$ & $\begin{array}{l}\mathrm{EA} \text { 를 수립하고 유지·개선하는 등 EA의 모든 활동 } \\
\text { 과 관련된 EA 업무 수행내용 및 기능 구조 }\end{array}$ & $\begin{array}{l}\text { EA방향과 원칙, EA 법제도 규정 및 지침, 투 } \\
\text { 자의사결정 체계, EA기능·프로 세스의 정보 } \\
\text { 화 횔동에 반영, 정보공유 및 상호운영 }\end{array}$ & \multirow{3}{*}{$\begin{array}{l}\text { 한국정보화 } \\
\text { 진흥원(2006)\& } \\
\text { 행정자치부 } \\
\text { (2005) }\end{array}$} \\
\hline & EA조직 & $\begin{array}{l}\text { EA관련 역할에 초점을 맞준 의시결정체계 } \\
\text { 및 조직구조로서 의사결정자 수준에서 실무자까지의 } \\
\text { 정보자원관리 관련 모든 책임과 역할을 정의 }\end{array}$ & $\begin{array}{l}\text { EA정보관리, EA조직 운용, EA리더십과 운영 } \\
\text { 통제, EA 역량개발 및 교유체계 }\end{array}$ & \\
\hline & EA인력 & $\begin{array}{l}\text { 수립된 EA를 운영관리하기 위해 담당할 } \\
\text { 영역별 아키텍트 }\end{array}$ & EA인력자질, 비전 목표인지, 투명 및 책임감 & \\
\hline
\end{tabular}

표 $2 \mathrm{EA}$ 역량의 조작적 정의 및 관련 연구

Table 2. EA capability operational definition \& reference 5

\begin{tabular}{|c|c|c|c|c|}
\hline \multicolumn{2}{|c|}{ 구분 } & 조작적 정의 & 측정 항목 & 관련 연구 \\
\hline \multirow{3}{*}{$\begin{array}{c}\mathrm{E} \\
\mathrm{A} \\
\text { 역량 }\end{array}$} & EA수립 & $\begin{array}{l}\text { 조직의 비전 및 목표에 이바지할 수 있는 현행이키텍처와 목표 } \\
\text { 아키텍처, 이행계획을 수립하는 역량 }\end{array}$ & $\begin{array}{l}\text { 성과체계, 업뮈데이터응용/기술 } \\
\text { 이키텍처, 이행전략 }\end{array}$ & \multirow{3}{*}{$\begin{array}{l}\text { 정보통신부\&한국 } \\
\text { 정보화진흥원 } \\
\text { (2006) }\end{array}$} \\
\hline & EA관리 & $\begin{array}{l}\text { 적절하게 수립된 정보기술 이키텍처를 조직에 적합하게 활용할 } \\
\text { 수 있도록 유지 관리하는 역량 }\end{array}$ & $\begin{array}{l}\text { EA형상관리, 아키텍처 통합, } \mathrm{EA} \\
\text { 전개, EA 기반 예산 수립 및 집 } \\
\text { 행, EA교육훈련 }\end{array}$ & \\
\hline & EA활용 & $\begin{array}{l}\text { 수립된 아키텍처를 이용하여 조직의 업무 및 전략 등과 연계하 } \\
\text { 여 전사적 성과를 향상시키는 역량 }\end{array}$ & $\begin{array}{l}\text { 전략연계, 기술통합, 업무향상, 정 } \\
\text { 보화사업 항상 }\end{array}$ & \\
\hline
\end{tabular}


상으로 $\mathrm{EA}$ 거버넌스와 $\mathrm{EA}$ 역량에 대해 분산분석을 실시하였 으며 EA 거버넌스와 EA 역량과의 연관관계를 검증하기 위해 구조방정식을 사용하여 $\mathrm{AMOS}$ 소프트웨어를 통해서 분석을 실시하여 전반적인 모형의 적합성을 검정하였다.

\section{3 신뢰성 및 타당성 분석}

본 연구에서는 측정도구에 대한 신뢰성을 검증하기 위해 측정도구 별로 내적 일치성을 평가하는 크롬바 알파 (cronbach's alpha) 계수를 사용하여 측정도구의 신뢰성을 분석 평가하였다. 일반적으로 신뢰성은 동일한 개념에 대해 반복적으로 측정했을 때 나타나는 측정값들의 분산을 의미하 는 것으로 동일한 측정도구를 이용하여 반복적으로 측정했을 때 동일한 측정값을 얻을 수 있다는 것을 의미한다.

표 3 은 신뢰성 검증결과를 보여주는 것으로 신뢰성 판단기준 인 크롬바 알파 값이 0.6 이상인 것으로 나타나 본 연구에서 사 용된 측정도구는 신뢰성을 가지고 있는 것으로 나타났다[24]. 표 3. 크롬바 알파 신뢰성 분석

Table 3. Cronbach's Apha Reliability Analysis

\begin{tabular}{|c|c|c|}
\hline 요인 & 항목수 & Cronbach's $a$ 계수 \\
\hline EA프로세스 & 6 & 0.808 \\
\hline EA조직 & 4 & 0.814 \\
\hline EA인력 & 3 & 0.825 \\
\hline EA수립 & 4 & 0.810 \\
\hline EA관리 & 5 & 0.762 \\
\hline EA활용 & 4 & 0.821 \\
\hline
\end{tabular}

또한 타당성 분석을 위해 본 연구에서는 각 변수들에 대한 선 행연구를 통한 이론적 고찰로 확인적 요인분석(Confirmatory Factor Analysis : $\mathrm{CFA}$ )을 추진하고자 한다.

기존의 이론이나 경험적인 연구결과로부터 분석대상이 되 는 변수에 대한 사전 지식이나 이론적 결과를 가지고 그 내용 을 가설형식으로 모형을 만들기 위한 방법이며 특정가설을 설 정하고, 이것이 자료에서 관찰되는 관계를 어느 정도 잘 설명 하고 있는가를 살펴보고자 하는 것이다.

또한 모형의 적합도를 살펴보는 $\mathrm{RMR}$ 은 0.05 이하이거나
0 에 가까울수록 바람직하다.

본 연구의 확인적 요인분석 결과는 표 4에서와 같이 구성 개념의 타당성은 확보되었다고 볼 수 있다.

\section{4 가설의 검증}

본 연구에서는 측정항목에 대하여 요인별 단일 차원성 확 인 및 통계적인 검정을 위해서 AMOS 18.0 패키지를 이용하 여 확인적 요인분석을 실시하였다.

카이제곱 검정은 모형의 완전성, 즉 모형이 모집단 자료에 완전하게 적합하다는 귀무가설을 검정한다.

연구모형의 연구결과를 확인하면 카이제곱 658.04 , 자유 도는 178 그리고 유의확률은 0.00 으로 나타났으며. 표 5 에 서와 같은 결과로 나타나 연구모형이 적합하지 않다는 결론을 내릴 수 있다.

연구모형을 토대로 적합한 모형을 찾아내기 위한 방법으로 연구모형에서 관계가능성을 나타내는 다중상관계수의 제곱 (Squared Multiple Correlations)과 보정지수(Modification Indices)를 이용하였으며. 이 보정지수는 전반적인 모형의 적합 도 개선을 나타내기 위한 것으로 관측되지 않은 개념간의 관계를 나타낸다.

즉, 카이자승의 감소상태를 나타낸다고 할 수 있다[25]

그러나 이러한 보정지수의 사용은 반드시 이론적으로 정당 화될 경우에만 사용가능하다[26].

또한 표 5 는 보정지수를 통해서 발견할 수 있는 보정모형 을 나타낸 것이다.

보정모형에서 구조방정식을 분석결과, 카이제곱 $=163.913, \quad$ 자유도 $(\mathrm{d} . \mathrm{f})=134, \quad \mathrm{p}$ 값=0.04, $\mathrm{GFI}=0.91$, AGFI $=0.85, \quad \mathrm{TLI}=0.97, \quad \mathrm{CFI}=0.91, \quad \mathrm{RMR}=0.05$ 로 나 타났다.

$\mathrm{AGFI}$ 의 판단 근거값은 기준치에 미치지 못하고 있으나 나머지 판단지수들은 만족스럽기 때문에 본 연구에서 보정모 형을 그림 3 과 같이 최종 모형으로 결정하기로 한다.

본 연구의 가설을 근간으로 $\mathrm{EA}$ 거버넌스와 $\mathrm{EA}$ 역량과의

표 4. 확인적 요인분석

Table 4. Confimatory Factor Analysis

\begin{tabular}{|c|c|c|c|c|c|c|c|c|c|c|c|}
\hline 구분 & 구성개념 & $\begin{array}{c}\text { CFA } \\
\text { 이전 } \\
\text { 항목수 }\end{array}$ & $\begin{array}{c}\text { CFA } \\
\text { 이후 } \\
\text { 항목수 }\end{array}$ & $\begin{array}{l}\text { 카이 } \\
\text { 제곱 }\end{array}$ & DF & $P$ & $\begin{array}{c}\text { CMIN } \\
\text { DF }\end{array}$ & GFI & RMR & TLI & $\mathrm{CF}$ \\
\hline \multirow{3}{*}{$\begin{array}{c}\text { EA } \\
\text { 거버넌 } \\
\text { 스 }\end{array}$} & EA프로세스 & 6 & 4 & \multirow{3}{*}{33.99} & \multirow{3}{*}{23} & \multirow{3}{*}{0.06} & \multirow{3}{*}{1.48} & \multirow{3}{*}{0.96} & \multirow{3}{*}{0.04} & \multirow{3}{*}{0.97} & \multirow{3}{*}{0.98} \\
\hline & EA조직 & 4 & 3 & & & & & & & & \\
\hline & EA인력 & 3 & 3 & & & & & & & & \\
\hline \multirow{3}{*}{$\begin{array}{l}\text { EA } \\
\text { 역량 }\end{array}$} & EA수립 & 4 & 4 & \multirow{3}{*}{36.04} & \multirow{3}{*}{30} & \multirow{3}{*}{0.21} & \multirow{3}{*}{1.20} & \multirow{3}{*}{0.96} & \multirow{3}{*}{0.03} & \multirow{3}{*}{0.98} & \multirow{3}{*}{0.99} \\
\hline & EA관리 & 5 & 3 & & & & & & & & \\
\hline & EA활용 & 4 & 4 & & & & & & & & \\
\hline
\end{tabular}


표 5. 주요 적합도 지수

Table 5. Habitat Suitability Indexes

\begin{tabular}{|c|c|c|c|c|c|c|c|c|}
\hline 모형 & 카이제곱 & 자유도 & $\mathrm{p}$ & $\mathrm{Q}$ & $\mathrm{GFI}$ & $\mathrm{AGFI}$ & $\mathrm{TLI}$ & $\mathrm{RMR}$ \\
\hline \hline 기초 모형 & 658.041 & 178 & 0.00 & 3.70 & 0.72 & 0.63 & 0.71 & 0.06 \\
\hline 보정 모형 & 163.913 & 134 & 0.04 & 1.22 & 0.91 & 0.85 & 0.97 & 0.05 \\
\hline
\end{tabular}

연관성을 검증한 연구가설 검정결과를 정리하면 표 5 와 같다.

당초 본 연구모형에서 설정한 $\mathrm{EA}$ 거버넌스의 핵심요인인 $\mathrm{EA}$ 기능·프로세스, $\mathrm{EA}$ 조직 그리고 $\mathrm{EA}$ 인력이 $\mathrm{EA}$ 역량을 이루는 각 속성인 $\mathrm{EA}$ 수립, $\mathrm{EA}$ 관리 및 $\mathrm{EA}$ 활용의 변수에 영 향을 주며 동시에 $\mathrm{EA}$ 수립이 $\mathrm{EA}$ 관리에 그리고 $\mathrm{EA}$ 관리가 $\mathrm{EA}$ 활용에 단계별로 영향을 주고 이것은 궁극적으로 조직의 $\mathrm{EA}$ 거버넌스가 $\mathrm{EA}$ 역량에 영향을 미치는 것을 가정하였다.

보정모형을 통해서 알 수 있는 것은 당초 설정한 한 대로 외생변수 EA 거버넌스의 구성개념인 $\mathrm{EA}$ 기능·프로세스 요 인이 내생변수인 $\mathrm{EA}$ 역량의 모든 구성요인인 $\mathrm{EA}$ 수립, $\mathrm{EA}$ 관 리, $\mathrm{EA}$ 활용 요인에 유의한 영향을 미치며, $\mathrm{EA}$ 거버넌스의 $\mathrm{EA}$ 조직 요인이 내생변수인 $\mathrm{EA}$ 역량의 $\mathrm{EA}$ 활용 요인에 유의 한 영향을 미치고, 외생변수 $\mathrm{EA}$ 거버넌스의 $\mathrm{EA}$ 인력 요인이 내생변수인 $\mathrm{EA}$ 역량의 $\mathrm{EA}$ 관리와 $\mathrm{EA}$ 활용 요인에 유의한 영 향을 미치는 것을 알 수 있다.

그리고 $\mathrm{EA}$ 거버넌스의 구성요인 $\mathrm{EA}$ 조직과 $\mathrm{EA}$ 인력이
타 시스템 연계 요인에, $\mathrm{EA}$ 거버넌스의 구성요인 $\mathrm{EA}$ 조직의 $\mathrm{EA}$ 조직운영 요인이 $\mathrm{EA}$ 역량의 구성요인 $\mathrm{EA}$ 수립의 예산투 자예방 요인에, $\mathrm{EA}$ 거버넌스의 구성요인 $\mathrm{EA}$ 조직의 $\mathrm{EA}$ 역량 교육 요인이 $\mathrm{EA}$ 역량의 구성요인 $\mathrm{EA}$ 수립의 $\mathrm{EA}$ 로드맵 이행 계획 요인에, $\mathrm{EA}$ 거버넌스의 구성요인 $\mathrm{EA}$ 조직의 $\mathrm{EA}$ 역할책 임 요인이 $\mathrm{EA}$ 역량의 구성요인 $\mathrm{EA}$ 관리의 $\mathrm{EA}$ 현행화 인지와 $\mathrm{EA}$ 수립의 예산투자예방 요인에 각각 유의한 영향을 미친다 는 것을 경로분석을 통하여 추가적으로 알 수 있다.

\section{IV. 결 론}

\section{1. 연구결과}

지금까지 국내에서 지속적으로 $\mathrm{EA}$ 사업이 진행되고 있는 공공부문을 대상으로 $\mathrm{EA}$ 거버넌스와 $\mathrm{EA}$ 역량의 연관관계가 있는지 실증적으로 분석하였다. 이에 대해서 $\mathrm{EA}$ 역량에 영향

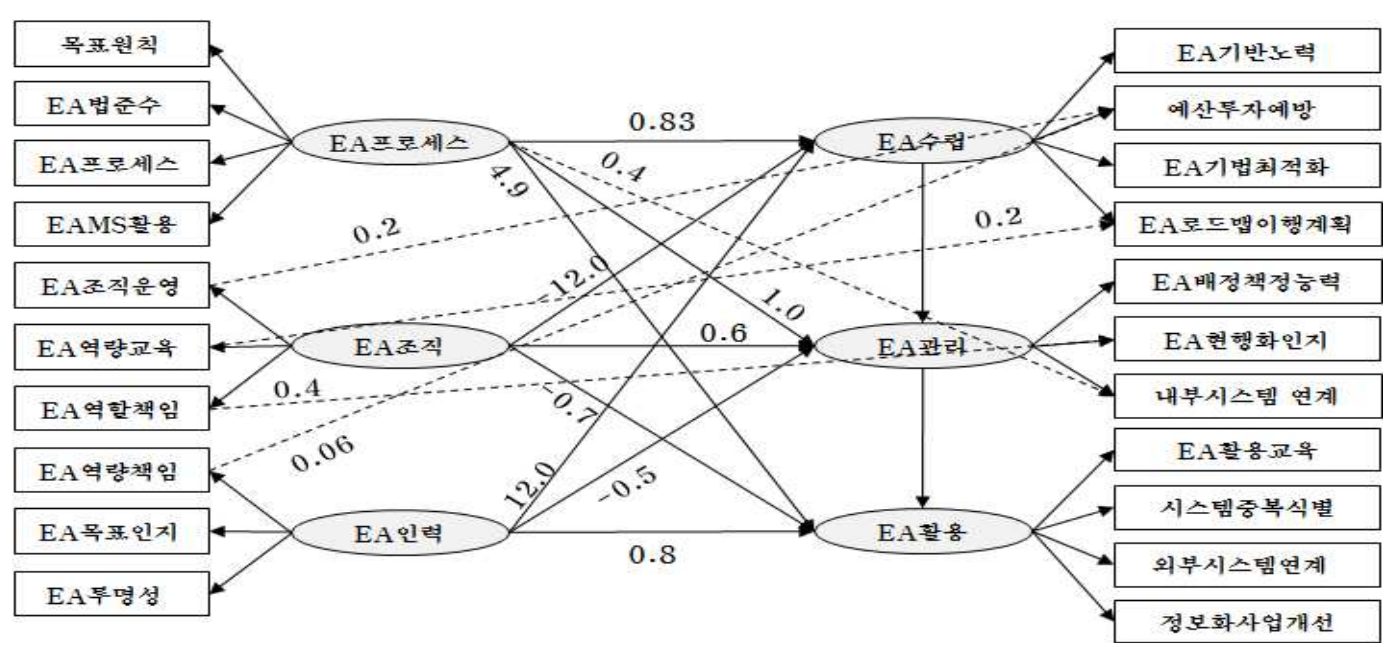

그림 3. 보정 모형

Fig. 3. Adjusted Model

$\mathrm{EA}$ 역량의 구성요인 $\mathrm{EA}$ 수립에는 영향을 주지 못하는 것을 알 수 있다.

또한 기본모형에서 설정하지 않았던 $\mathrm{EA}$ 거버넌스의 구성 요인 $\mathrm{EA}$ 기능·프로세스가 $\mathrm{EA}$ 역량의 구성요인 $\mathrm{EA}$ 관리의
을 미치는 주요 변수를 대상으로 한 가설검증 내용을 정리하 고 주요 시사점을 제시한다.

김형진 외[27]에 따르면 $\mathrm{EA}$ 관련 전담부서 및 아키텍트가 존재하는가 ?'에 대한 질문에 공공기관 $15 \%$, 일반기업 $34 \%$ 
만이 '있다' 라고 응답하여 국내 $\mathrm{EA}$ 부문에서의 $\mathrm{EA}$ 전담조직 에 대한 관심이 크지 않다는 연구결과에 비추어 보면 일반적 으로 $\mathrm{EA}$ 거버넌스가 잘 적용되면 역량은 강화된다고 인식하 고, 또한 공공부문은 법제도적으로 조직차원에서 반드시 $\mathrm{EA}$ 조직 및 $\mathrm{EA}$ 인력이 구성되어 있어 $\mathrm{EA}$ 수립 및 적용에 잘 대응 한다고 예상할 수 있지만 실제 정보화 현장은 $\mathrm{EA}$ 전담 조직과 역할 - 책임을 전담하는 인력을 편성하여 운영하는 것 보다 다 른 정보화 업무와 겸임하는 형태로 조직을 편성하여 업무를 수행하는 것이 일반화되어 있어서 이와 같은 결과가 나온 것 으로 볼 수 있으며 본 연구의 검증결과에서 나타난 $\mathrm{EA}$ 수립 단계에 $\mathrm{EA}$ 조직 및 $\mathrm{EA}$ 인력의 역할이 부재하다는 결과와 유 사한 현상이라 여겨진다.

이것은 $\mathrm{EA}$ 를 처음 도입구축 시 준비가 제대로 안된 시점 에서 $\mathrm{EA}$ 에 대한 충분한 교육을 이수한 인력과 전담 조직이 갖추어지지 않은 상태에서 $\mathrm{EA}$ 를 수립하는 경우 $\mathrm{EA}$ 역량을 확보하기는 어렵다는 것을 짐작 할 수 있으며, 또한 $\mathrm{EA}$ 조직 수준이 $\mathrm{EA}$ 수립에 그 다지 영향을 미치지 못하는 것은 대부 분의 공공기관들이 처음 $\mathrm{EA}$ 도입구축 작업 시에 내부적으로 전문가 부족으로 인하여 외부 관련 전문가에 아웃소싱으로 의 존하여 구축하는 경우에 의한 결과라고 볼 수 있다.
수 있는 역량을 가질 수 있다고 보아진다.

$\mathrm{EA}$ 전담조직의 설치 및 구성도 중요하지만 정보자원관리 의 체계화를 통한 전사 정보화 투자효율성 증대를 위해 $\mathrm{EA}$ 의 활용 극대화를 위해서는 가장 먼저 해야 할 일은 각 업무팀의 정보화사업 관련담당자인 $\mathrm{BA}$ (Business Architect)가 지속 적으로 조직의 정보화 사업 프로세스 상의 모든 단계인 IT사 업계획, 추진 검토 및 예산 수립, 요구사항관리, 사업발주 제 안서 그리고 사업수행에서의 분석, 설계, 개발 및 운영유지관 리에서 의사결정 및 모니터링을 지원할 수 있도록 조직적 변 화를 해야 한다.

기존 조직형태 속에서 각 업무팀의 $\mathrm{BA}$ 를 $\mathrm{EA}$ 활동에 가능 한 한 많이 참여시킬 수 있도록 $\mathrm{BA}$ 가 속해 있는 수직적 구조 의 팀업무와 $\mathrm{EA}$ 업무 활동을 위한 업무기능을 혼합한 매트릭 스구조 형태의 조직운영 구조를 도입하고 동기부여 차원에서 내부적으로 개인 및 조직업무 성과측정에 반영하는 등 조직적 변화를 통하여 운영하면 $\mathrm{EA}$ 역량 강화는 물론 정보화 성과 향상에 많은 도움이 될 수 있을 것이다.

특히 규명하고 싶은 $\mathrm{EA}$ 거버넌스 하에서 $\mathrm{EA}$ 기능 - 프로세 스에 따라 $\mathrm{EA}$ 역량 간의 단계적이고 순서적으로 $\mathrm{EA}$ 활동을 수행하면 수준이 증대 될 것인가에 대해서는 내생변수 $\mathrm{EA}$ 역

표 6. 가설 검정 결과

Table 6. Hypothesis Test Result

\begin{tabular}{|c|c|c|c|c|c|c|c|c|c|}
\hline & \multirow{3}{*}{\multicolumn{2}{|c|}{ 가 설 }} & \multicolumn{3}{|c|}{ 경로계수 } & \multirow{3}{*}{$\begin{array}{l}\text { 검정 } \\
\text { 통계량 }\end{array}$} & \multirow{3}{*}{$\begin{array}{l}\text { 유의 } \\
\text { 확률 }\end{array}$} & \multirow{3}{*}{$\begin{array}{l}\text { 채택 } \\
\text { 여부 }\end{array}$} & \multirow{3}{*}{ 비고 } \\
\hline & & & \multicolumn{2}{|c|}{ 비표준화 } & \multirow{2}{*}{$\begin{array}{l}\text { 표준화 } \\
\text { 계수 }\end{array}$} & & & & \\
\hline & & & 계수 & $\begin{array}{l}\text { 표준 } \\
\text { 편차 }\end{array}$ & & & & & \\
\hline \multirow{3}{*}{$\begin{array}{l}\text { EA기능· } \\
\text { 프로세스 }\end{array}$} & $\rightarrow$ & EA수립 & 1.000 & & 0.834 & & & & \\
\hline & $\rightarrow$ & EA관리 & 1.924 & 0.308 & 1.013 & 6.254 & $* * *$ & 채택 & \\
\hline & $\rightarrow$ & EA활용 & 6.096 & 2.811 & 4.819 & 2.169 & $0.03(*)$ & 채택 & \\
\hline \multirow{3}{*}{ EA조직 } & $\rightarrow$ & EA수립 & -13.124 & 13.399 & -12.085 & -0.980 & 0.32 & 기각 & \\
\hline & $\rightarrow$ & EA관리 & 1.000 & & 0.581 & & & & \\
\hline & $\rightarrow$ & EA활용 & -0.786 & 0.350 & -0.686 & -2.242 & $0.02(*)$ & 채택 & \\
\hline \multirow{3}{*}{ EA인력 } & $\rightarrow$ & EA수립 & 14.143 & 14.216 & 12.303 & 0.995 & 0.32 & 기각 & \\
\hline & $\rightarrow$ & EA관리 & -0.969 & 0.191 & -0.531 & -5.079 & $* \star *$ & 채택 & \\
\hline & $\rightarrow$ & EA활용 & 1.000 & & 0.824 & & & & \\
\hline EA수립 & $\rightarrow$ & EA관리 & -0.318 & 0.144 & -0.200 & -2.209 & $0.03(*)$ & 채택 & \\
\hline EA관리 & $\rightarrow$ & EA활용 & -3.153 & 1.569 & -4.737 & -2.010 & $0.04(*)$ & 채택 & \\
\hline EA프로세스 & $\rightarrow$ & 내부시스템 연계 & 0.691 & 0.677 & 0.406 & 1.022 & 0.31 & 기각 & 새 가설 \\
\hline EA조직운영 & $\rightarrow$ & 예산투자예방 & 0.236 & 0.155 & 0.217 & 1.521 & 0.13 & 기각 & 새 가설 \\
\hline EA역량교육 & $\rightarrow$ & EA로드맵이행계획 & 0.281 & 0.057 & 0.260 & 4.913 & $* * *$ & 채택 & 새 가설 \\
\hline EA역할책임 & $\rightarrow$ & EA현행화인지 & 0.366 & 0.064 & 0.370 & 5.684 & $* \star *$ & 채택 & 새 가설 \\
\hline EA역량책임 & $\rightarrow$ & 예산투자예방 & 0.066 & 0.117 & 0.058 & 0.561 & 0.58 & 기각 & 새 가설 \\
\hline
\end{tabular}

$(* * *: \mathrm{p}<0.001, * *: \mathrm{p}<0.01, *: \mathrm{p}<0.05)$

따라서 실무적 관점에서 이를 효과적으로 대응하기 위해서 는 먼저 국가적으로 관련 예산을 충분히 확보하여 조직의 법 제도적 차원에서 $\mathrm{EA}$ 전담조직과 전담인력인 $\mathrm{EA}$ 아키텍처별 아키텍트를 먼저 구성하여 추진 관리하면 자체적으로 해결할
량의 첫 번째 구성요인 $\mathrm{EA}$ 수립 역량의 수준에 따라 두 번째 단계인 $\mathrm{EA}$ 관리 역량에 영향을 미치는지와 두 번째 단계인 $\mathrm{EA}$ 관리 역량의 수준을 통해서 세 번째 $\mathrm{EA}$ 활용 역량에 유의 한 영향을 주는지에 대해서는 각 단계별 역량에 상호 충분히 
영향을 주는 것으로 검증결과가 도출되었다.

이것은 전사차원의 계층화된 조직구조에서 $\mathrm{EA}$ 도입 초기 에 제대로 갖추어진 $\mathrm{EA}$ 거버넌스 구성요소인 $\mathrm{EA}$ 기능- 프로 세스에 따라 각 단계적으로 충분한 역량수준을 가져야만 전체 $\mathrm{EA}$ 활동수준을 높일 수 있는 것으로 보아지며, $\mathrm{EA}$ 를 체계적 인 운영관리를 하려면 우선적으로 $\mathrm{EA}$ 를 제대로 구축된 후에 이런 결과가 나타나며, 또한 $\mathrm{EA}$ 를 효율적으로 활용하기 위해 서는 반드시 $\mathrm{EA}$ 조직차원에서 체계적으로 운영관리를 수행 해야 한다는 선순환적 형태를 가지는 것으로 보아진다.

이와 더불어 $\mathrm{EA}$ 거버넌스의 구성요소인 $\mathrm{EA}$ 기능 - 프로세 스 이외의 요인인 원칙, 규정 및 지침 측면에서 분석결과를 보면 공공부문의 $\mathrm{EA}$ 도입 법률에 의한 범정부적으로 표준화 되어 있는 구축목적과 그에 따른 프레임워크 구성, 각각의 공 공기관별로 정의되어 있는 전략적 목표, 원칙, 규정 및 지침 에 전 직원들이 준거하고 체계적인 $\mathrm{EA}$ 활동을 수행함으로써 $\mathrm{EA}$ 역량요인인 $\mathrm{EA}$ 수립, $\mathrm{EA}$ 관리 및 $\mathrm{EA}$ 활용의 세 가지 역량 수준을 향상시키는데 있어서 중요한 역할을 할 수 있다는 것 을 알 수 있었다.

본 연구결과를 요약하여 보면 아래와 같이 정리할 수 있다.

첫째, $\mathrm{EA}$ 도입, 구축 시 사전에 전사적 경영목표와 정보화 비전과 연계하여 $\mathrm{EA}$ 를 활용하는 업무팀과 $\mathrm{EA}$ 를 운영관리하 는 정보시스템 부서를 유연하게 조직화하고, $\mathrm{EA}$ 도입 목적이 나 목표에 따라 $\mathrm{EA}$ 담당 인력들에게 역할과 책임을 부여한 후 충분한 교육과 사전 준비가 있어야만 전사적 정보화 활동에서 산출되는 정보자원을 제대로 운영관리할 수 있다.

그리고 $\mathrm{EA}$ 추진계획에 따라 도입, 구축하는 초기단계에서 우선 수립된 $\mathrm{EA}$ 거버넌스의 구성요인인 $\mathrm{EA}$ 기능·프로세스 에 따라 효과적으로 수행하려면 먼저 전사차원에서 $\mathrm{EA}$ 조직 과 $\mathrm{EA}$ 인력을 얼마나 체계적으로 잘 준비하고 구조화하는가 에 따라 $\mathrm{EA}$ 수립, $\mathrm{EA}$ 관리 및 $\mathrm{EA}$ 활용 역량을 향상시키는데 있어서 중요한 역할을 할 수 있다는 것을 알 수 있었다.

둘째, 새로운 가설을 통해서 알 수 있는 것은 내부적으로 구성된 $\mathrm{EA}$ 조직의 $\mathrm{EA}$ 인력에 대한 역량 개발 및 증대에 필요 한 지속적인 교육지원이 더욱 필요하며, $\mathrm{EA}$ 로드맵 및 이행계 획 등에 따라 $\mathrm{EA}$ 현행화 업무 등을 충분히 수행할 수 있도록 내부 업무 성과보상과 연계하여 $\mathrm{EA}$ 에 대한 책임과 역할을 강 화하는 것이 필요하다는 것이다.

전사 차원에서 $\mathrm{EA}$ 를 추진하기 전에 $\mathrm{EA}$ 활동의 핵심체계인 $\mathrm{EA}$ 거버넌스의 요인인 $\mathrm{EA}$ 기능 - 프로세스, $\mathrm{EA}$ 조직 및 인력 등 핵심요소를 적극적으로 구성하여야 하며, 무엇보다 충분한 역량을 발휘할 수 있는 전담조직 및 인력체계와 인력에 대한 역량개발 및 교육체계를 갖추어져야만 $\mathrm{EA}$ 를 제대로 적용하
여 활용할 수 있고 더 나아가 정보자원관리의 기반으로서 그 활용도가 높아질 수 있다는 것도 알 수 있다.

\section{2. 연구의 한계 및 향후 연구과제}

본 연구의 한계로는 효과적인 정보화를 위한 정보자원관리 에 실질적으로 $\mathrm{EA}$ 를 활용하는 정보화 수요조직의 관련 업무 프로세스 및 기능을 담당하는 $\mathrm{BA}$ 를 포함시키지 못하고, 정보 화 부문의 $\mathrm{EA}$ 관련 직 - 간접 담당자들을 대상으로만 조사를 실시한 것이 다소 아쉬운 점이다.

2005 년 법률 제정 후 $\mathrm{EA}$ 를 현업에서의 활용보다는 정보 화 관련 조직에서 $\mathrm{EA}$ 를 유지관리 위주로 운영하고 있는 경우 도 있어 조직들 간 어느 정도의 역량과 성숙도에 따라 좀 더 균형된 연구를 수행하지 못하여 향후에는 이러한 점들을 감안 한 연구가 필요하다.

마지막으로 이번 연구는 의무적으로 도입해야 하는 공공부 문을 대상으로 수행했지만 향후 국내 전체 기업을 대상으로 한 관련연구가 필요하리라 본다.

\section{참고문헌}

[1] John, A., Elaine, W., "CIO Council : A Practical Guide to Federal Enterprise Architecture", Software Technology Conference Tutorial, pp.19, 2002.4.

[2] Zachman, J. A, "A Framework for Information System Architecture", Vol.26, No.3, pp.276-277. 1987.9.

[3] ITアソシエイト協義會, “EA策定 ガイドライン”, pp.1-2, 2005 (本成 15 年). 12.

[4] IEEE, "ANSI/EEE Std. 1471-2000 Recommended Practice for Architectural", pp.176, 2000.11.

[5] OMB, "Circular A-130 Management of Federal Information Resource", Revision, Vol.65, No.72, 2000.3.

[6] swoh, jwkim, "The Impact of Using Information Technology Architecture on IT Capability and IT Performance : Focused on Public Agencies", Korea Society of IT Services, Vol.7, No.2, pp.26, 2008.3. 
[7] ydhong, "An Empirical Study on the Factors Influencing the Adoption of Enterprise Architecture", JungAng Univ., Dept. of Biz. \& Administration, Master's Thesis, pp.13, 2006.12.

[8] skkim, hjpark, "Why Firms Need to Bring in Enterprise Architecture and How it ould be Introduced?", Information Systems Review, Vol.4, No.2, pp.27-28, 2002.12.

[9] Korea Computerization Agency, "A study on the effectiveness measurement model through analyzing the cases of Information Technology Architecture", pp.6, 2003.11.

[10] hkmoon, "A Case Study of IT Architecture Implementation: Office of Postal Service-Korea Post", Information Systems Review, Vol.9, No.3, pp.184, 2007.12.

[11] Korea Computerization Agency, "Study on Effectiveness Measurement Model through Analyzing Introduction Case of ITA/EA", pp.77-84, 2003.9.

[12] Health Insurance Review \& Assessment Service, "Development of an EA Management System based on System Integration", ITA society, Vol.8, No.2, pp.61-62, 2011.6.

[13] Bharadwaj, Anandhi, "A Resource-Based Perspective on Information Technology Capability and Firm Performance: An Empirical Investigation", MS Quarterly, Vol. 24, No. 1, pp.176, 2000.3.

[14 Ross, J. W., Cynthia M. B., Dale. L. G., "Develop Long-Term Competitiveness through IT Assets", Sloan Management Review, pp.31-32, 1996.Fall.

[15] Henderson, J.C. and Venkatraman, N., "Strategic Alignment:Leveraging Information Technology for Transforming Organization”, IBM Systems Journal, Vol.32, No.1, pp.472-484, 1993.9.

[16] swoh, "A Study on ITA Maturity Model in Public sector", ITA society, Vol.2, No.2, pp.61-62, 2005.6 .

[17] swoh, sashin, dushin, "ITA Maturity Integration Model for Goverment", Korea Society of IT Services, pp.225-226, 2007.9.
[18] jyjung, "Study on EA Maturity Change by EA \& ISP Implementation Type”, KookMin Univ. Biz. IT School, Master's Thesis, pp.41-42, 2006.12.

[19] jschoi, htkim, "Building SOA Govemance relating with EA Governance", Korea Society of IT Services, pp.231-232, 2007.9.

[20] Ministry of Government Administration and Home Affairs, "e-Government EA Implementation Guide(A modified version)”, pp.161-221, 2008.1.

[21] Peterson, R. R., "information strategies and tactics for Information Technology governance". In W. Van Grembergen (Ed.), "Strategies for Information Technology Governance", Hershey, PA: Idea Group Publishing, pp.4-37, 2003.9.

[22] Ministry of Knowledge Economy, Korea Computerization Agency, "ITA Maturity Model 1.0(Draft)", pp.4-6, 2006.8.

[23] Korea Computerization Agency, "ITA Maturity Model v2.2 Guide Book”, pp.1, 2009.9.

[24] ghlee, "Society Scientific Methodology[A modified version]”, bobmunsa, pp.86, 2008.7.

[25] Hair Jr., J. F., Anderson, R. E. Tatham, R. L., Black, W. C., "Multivariate Data Analysis 5th", Prentice Hall, pp.9, 1998.3.

[26] gskim "A Study on the Service Operation Activities of the Customer-Oriented for the Customer Satisfaction", SeMyung Univ. Dept. of Kyungsang College, pp.87, 2001.6.

[27] hjkim, ksyang, shjuhn, "A Study on the Status of ITA/EA Initiatives in Korea*", Korea Society of IT Services, Vol.5, No.3, pp.63-82, 2006.12.

[28] ysAhn, hwKim, "Influence Factors on IT Governance from ITA/EA Functions", The Korea Society of Computer and Information, Vol.14, No.6, pp.144-146, 2009.6.

[29] hsJoo, "A Study on Web accessibility situation of Public Institution and Major it Companies Institutions", The Korea Society of Computer and Information, Vol.14, No.10, pp.181-185, 2009.10 . 


\section{저 자 소 개}

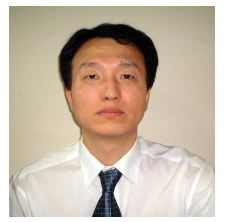

김 기 백

1993: 중앙대학교 경영정보학과 경영 학석사

2012: 건국대학교 벤처전문기술학과 공학박사수료

현재: 한국TT감리컨설팅 수석

관심분야: EA\&ISP, IT감리\&보안, 소셜네트워크 모바일\&빅 데이터

Fmail : kgbconsulting@hanmail.net

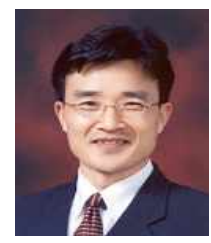

이 철 규

1991: 일본게이오대학교 관리공학 공 학석사

1997: 일본게이오대학교 바이오기술 공학박사

현 재: 건국대학교 기술경영학과 교수, 벤처창업지원센터장

관심분야: 벤처기술경영, 벤처창업

Email : cglee@konkuk.ac.kr

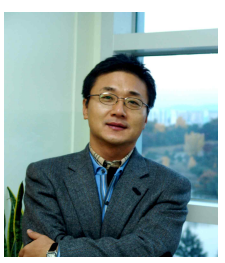

유 왕 진

1986: 미시간웨인주립대학교 산업및 제조공학과 공학석사

1990: 미시간웨인주립대학교 산업및 제조공학과 공학박사

현 재: 건국대학교 산업공학과 교수, 신산업융합학과 교수

관심분야: 산업공학 $(\mathrm{IE})$ 및 기술경영 (MOT)

Email : wjyoo@konkukac.kr

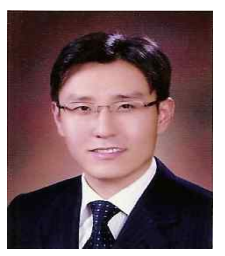

문 종 범

2000: 서울대학교 경영학과 경영학 석사

2005 서울대학교 경영학과 경영학 박사

현 재: 건국대학교 벤처전문기술학과, 신산업융합학과 부교수

관심분야: 벤처경영, 공급사슬관리, 서 비스 경영, IT경영

Email : jmoon@konkuk.ac.kr 